\title{
Practical Dilemma and Optimization Strategies for the Physical Education Curriculum in Chinese Schools in the New Era
}

\author{
Zhengpeng Shan, Linhai Shao* \\ Mudanjiang Normal University, Mudanjiang 157011, China \\ *Corresponding author: Linhai Shao, mdjslh@163.com
}

\begin{abstract}
Based on the Party's school sports development concept and in view of the practical problems of sports practice faced by the schools, this study uses literature research, logical reasoning, expert interviews, and other research methods to review, analyze, as well as reflect on the current development of physical education curriculum existing in schools and propose feasible optimization strategies in line with the "core qualities of sports disciplines" training.
\end{abstract}

Keywords: New era; China; School sports; Practice dilemma; Optimization strategy

Publication date: October 2021; Online publication: October 29, 2021

\section{Introduction}

In April 2020, the promulgation of "Opinions on Deepening the Integration of Physical Education and Promoting the Healthy Development of Adolescents" indicates that the Party and the State is emphasizing more and more on physical education among adolescents. Cultivating all-rounded socialist builders and successors in terms of physical, intellectual, moral, and labor points out the direction for the future progress of sports in schools. Facing the torrent of reform, it is necessary to examine its current development based on the Party's school sports development concept, analyze and reflect on the difficulties existing in the practice of school physical education curriculum, as well as suggest feasible optimization strategies in line with the cultivation of "core qualities of sports disciplines."

\section{Analysis on the practical dilemma of physical education in schools in the new era}

\subsection{General emphasis on the goal of the content and the weight of sports function}

Sports function refers to the role and effectiveness that sports have toward individuals and the society. It mainly depends on the attributes of sports itself and the needs of individuals or the society, in which the function of sports always changes along with the social form and needs. During the founding of the People's Republic of China, the goal of the physical education curriculum in schools from the late Qing Dynasty and the beginning of the "military nationals" to the early period of the founding of "health first, learning second," as well as to the 21 st century of "sports character, sports ability, healthy behavior" as the leading core literacy of sports disciplines ${ }^{[1]}$ has undergone a huge transformation. However, the function of sports is increasingly burdened. At this stage, the physical education syllabus in China's schools needs to assume more functions, including competitive sports selection, life safety education, core literacy construction, social adaptation, and "goal-oriented content," to explain the relationship between curriculum objectives and content ${ }^{[2]}$ as well as emphasize the use of physical education curriculum to achieve the goal. The autonomy of physical education curriculum is lost, logical subjects are no longer part of its curriculum, its 
curriculum exists in order to achieve or promote a number of established goals, and its lessons are focused on completing the outline indicators of the "factory," only to produce qualified "products." In view of that, students' positive experience of sports has long been lacking and physical education has gradually become a purgatory in the mouth of students, where "the most painful thing in the world is to run 800 meters."

\subsection{Discrimination of sports is dependent, and its "deputy" consciousness is serious}

Teachers are the beacons for students' growth, and they are the gardeners who care for students to thrive. Teachers should be respected by the public, but physical education teachers have always been neglected or even criticized, suffering from a lot of prejudice from inside and outside the industry. In traditional Chinese culture, the ideas of "Zhongwen to suppress martial arts," "heavy text to light martial arts," as well as "learning and excellence" have profoundly influenced the educational thinking in China ${ }^{[3]}$. From rejecting physical education teachers as head teachers and mathematics being taught by physical education teachers to the negative evaluation of sports practitioners by the society, it seems that these phenomena are only increasing. Psychology believes that the human nervous system has a "complete drive" function; that is, in light of incomplete understanding or unproven things, people would always tend to move in the direction of subjective thought of guesses, so that things would be a understood as a complete whole and the results of these guesses are often people's subconscious "self-righteous facts."

Cai Yuanpei once said, "Complete personality, first in sports, should put sports first." Sports do not only emphasize on the improvement of physical fitness, but also on the training of "social people." In the public-orientated "score first theory," the physical education in schools has long been subjected to the traditional concept of the "shackles," where physical education lessons are "crowded" for no reason, physical education courses are "compressed," physical education has become a "vassal" for cultural lessons, and physical education teachers have become associate teachers. It is understood that with good academic performance, everything is good, and sports do not matter. In recent years, with the joint efforts of the Party and many sports workers, the physical education curriculum in primary and secondary schools has been well developed, and there is a gradual increase in terms of social concern. However, in view of the education system in schools, physical education is still in the "deputy" status with insufficient attention, insufficient funds for subject construction, lack of space and equipment, as well as the "no class hours" phenomenon.

\subsection{Unsound evaluation system}

The benign development of school education cannot be separated from the scientific student evaluation system, in which the scientific learning evaluation system is based on excellent school education ${ }^{[4]}$. Such as in Table 1, through comprehensive comparison, the evaluation system of the three subjects tends to be complete, and their curriculum structure includes basic courses as well as elective courses. From the beginning of the semester to the end of the semester, from classroom homework to homework, all stages have their corresponding evaluation and assessment settings in order to facilitate targeted teaching. On the contrary, in regard to the physical education curriculum, its evaluation system has not been perfected, the assessment of students' skills is only carried out at the end of the period, the degree of assessment is still weak, and its homework layout is arbitrarily perfunctory. In addition, with the lack of phased evaluation, teachers are unable to receive timely feedbacks from students; thus, they are only able to judge the situation of students by their own subjective feelings (skills, learning attitude, etc.) to modify their methods of teaching. In this way, teachers' teaching and students' learning are out of touch, seriously hindering the development of physical education lessons. Its fixed examination promotes a fixed teaching, a fixed school, and the students' interests, hobbies, and skills are restricted only in terms of the physical examination. 
Table 1. Comparison of the evaluation systems of Chinese, Mathematics, and English with physical education in primary and secondary schools

\begin{tabular}{lll}
\hline & Comparison of evaluation systems & \\
\hline Subject & Chinese, Mathematics, English & Physical education \\
Course structure & Basic courses, elective courses & Basic courses, community electives \\
Classroom $\quad$ The mode of instruction & Teach and learn & Teach and learn \\
evaluation Indicator/standard & Stage exam argumentation & None (or non-systematic) \\
Post-class evaluation & Homework after classes & None \\
Post-school evaluation & Homework & Physical activity (random) \\
Monthly reviews & Monthly exam & None \\
Mid-term evaluation & Midterm & None \\
Final evaluation & Final & Final assessment (technical and \\
& & physical fitness) \\
Senior high school entrance examination & Knowledge content is flexible & Three techniques and comprehensive \\
& & evaluation \\
College entrance examination & Knowledge content is flexible & None \\
\hline
\end{tabular}

\section{Improvement and optimization strategies}

\subsection{Strengthening the cognition of physical education teaching with dialectically unified goal and content}

In different eras, sports bear different historical responsibilities, leading to different positioning and requirements of physical education. "Healthy China 2030" has clearly stated that primary and secondary schools are the focus of school health education, and the focus of physical health interventions would be among adolescents. When sports focus only on school sports and emphasize on goal-dominated content, the autonomy and spontaneity of sports are lost to a certain extent; in addition, the lack of competitions and systematic training has further led to poor performance. To this end, the core literacy of the new century primary and secondary school physical education curriculum should be optimized from the following aspects:

(1) physical education in primary and secondary schools should emphasize on the autonomy of its curriculum, eradicate the idea of goal-oriented content, as well as promote a mutual influence of its goal and content with the times and dialectical unity without any absolute lead;

(2) emphasize the benign experience of students during physical education lessons, encourage the return of "fun" in sports to physical education lessons, and promote the enthusiasm for sports among students;

(3) its curriculum design should be more flexible under the guidance of the outline while paying attention to sports autonomy, the effective use of sports games, and eliminating formal teaching;

(4) promote more specific and scientific phased goals, and ensure the teaching goals at different levels are in line with the actual situation of the students without blindly imitating the classic case.

\subsection{Alleviating the contradiction of "body and education" and focusing on the change of teachers' value orientation}

Several scholars have pointed out that the forerunners of the sports industry in China originated from Wuren 
Group during the Spring and Autumn period. The social status of martial arts gradually fell during the Warring States period and sank to the bottom of society after being persecuted by various dynasties during the imperial period. Under the banner of the Party and the State, the sports of great power and the sports of the country seem to be rising, but they do not change the stereotype of the Chinese people toward sports and athletes. In order to fundamentally alleviate the contradiction of "body and education" as well as the consciousness of "deputy" curriculum, it is essential to begin from the confidence of physical education teachers toward the industry, then establish a positive image in the society through certain works and enhance the status of the curriculum with relevant systems. As Lu Yuanzhen once said, "Physical education teachers should make effort for self-improvement, build their self-esteems, and be self-discipline in order to defend their professional honor, continuously improve their own cognitive and business level, strictly abide by professional ethics, as well as follow the social development.

In addition, the choice of reasonable value orientation provides direction for the professional development of physical education teachers in primary and secondary schools. Their professional development should adhere to a certain value orientation while advocating the orientation of "inspire teachers' professional autonomy," and adhering to "core physical education" cultivation as the goal of the orientation as well as the "communication, cooperation, and collaboration" orientation ${ }^{[5,6]}$.

\subsection{Promoting a structured evaluation system and a flexible selection of physical education examination programs}

Educational objectives and assessments are interrelated and closely related. The countereffects of assessment in the education system can be positive or negative, either promoting or hindering the achievement of the educational objectives. The existing evaluation system is flawed, thus hindering the positive development of the curriculum. This does not only aggravate the inertia of the teachers' team, but also indirectly lead to the tendency of the old-style model in the selection of physical education examination items. In order to avoid the above situation, the first step is to promote the improvement of the existing evaluation system.

(1) Quantify special technology, health knowledge, and ideological character, pay attention to the assessment, as well as integrate the school physical education curriculum into mid-term assessment and final assessment.

(2) Advocate the assessment of students' physical fitness, movement mastery, tactical execution, teamwork, and other abilities through competitions.

(3) Advocate the " $2 \mathrm{X}+\mathrm{Y}$ " sports test mode; that is, mass sports should be tested (track, foot, basket, row, dance, body, etc.), self-selected and local characteristics of the project should be tested (ice, snow, horse, shooting, martial arts, etc.), as well as self-selection of popular projects (exercise, net, feather, tour, slug, air, etc.) in full respect for students' interest in learning while reflecting local characteristics.

(4) The sports stage results should be incorporated into the examination results in a certain proportion, starting from the construction of the core literacy of the discipline to the five aspects of evaluation ad assessment: sports habits, sports technology, social adaptation, physical and mental health, as well as physical and mental cultivation.

\section{Funding}

This study was supported by the 2021 Mudanjiang Normal University Graduate Science and Technology Innovation Key Projects; 2021 Mudanjiang Normal University Graduate Science and Technology 
Innovation General Items (Number: Kjcx2021-026mdjnu; Kjcx2021-126mdjnu).

\section{Disclosure statement}

The authors declare that there is no conflict of interest.

\section{References}

[1] Ministry of Education, 2017, Ministry of Education of the People's Republic of General High School Physical Education and Health Curriculum Standards, People's Education Press, Beijing, 1-3, 6, 104.

[2] Mao Z, 2019, Review and Reflections on the Teaching Reform of Physical Education Curriculum in Primary and Secondary Schools in the Last 20 Years. Journal of Shanghai Institute of Physical Education, 43.

[3] Xu J, Lin H, 2020, Rejection of Pride and Prejudice: Discrimination, Root Causes, and Dissolving of Physical Education Teachers. Journal of Jilin Institute of Physical Education, 36(01): 80-83.

[4] Zhou W, 2014, Research on Institutional Difficulties and System Design in the Integration of Physical Education. Nanjing University.

[5] Shao L, 2016, Research on the Professional Development of Physical Education Teachers in Local Colleges and Universities. Northeast Normal University.

[6] Shao L, Qu T, 2015, The Dilemma and Countermeasure of the Professional Development of Physical Education Teachers in Local Colleges and Universities, Ecological Orientation, Education Theory and Practice, 35(551): 40-42. 